\title{
Prevalence of vaginal infection in 15 to 24 years women in Ouagadougou, Burkina Faso
}

\author{
Christelle W. Nadembega ${ }^{1}$, Florencia Djigma ${ }^{1}$, Djeneba Ouermi ${ }^{1}$, Simplice D. Karou ${ }^{2 *}$, Jacques Simpore ${ }^{1}$ \\ ${ }^{1}$ Centre de Recherche Biomoléculaire Pietro Anigonni (CERBA/LABIOGENE), Université de Ouagadougou, Burkina Faso. \\ ${ }^{2}$ Ecole Supérieure des Techniques Biologiques et al.imentaires (ESTBA-UL), Université de Lomé, Togo.
}

\begin{tabular}{l} 
ARTICLE INFO \\
\hline Article history: \\
Received on: $20 / 07 / 2016$ \\
Revised on: $23 / 09 / 2016$ \\
Accepted on: 05/10/2016 \\
Available online: $31 / 01 / 2017$ \\
\hline Key words: \\
Vaginal infection, \\
microorganism, antibiotic, \\
antifungal, Burkina Faso.
\end{tabular}

\section{INTRODUCTION}

UNAIDS in its fact sheet on global statistics in 2014 estimated that 39.6 million people were living with HIV worldwide. In Sub-Saharan Africa, 25.8 million people are infected and women represent more than the half of people living with HIV. According to recent the reports of UNAIDS, $66 \%$ of new global infections happen in sub-Saharan Africa (UNAIDS, 2014). HIV belongs to the huge panel of sexually transmitted pathogens, the most famous being Neisseria gonorrhoae, Chlamydia trachomatis, Treponema palidum, herpes simplex virus type 2, Human Papillomavirus, Hepatitis B, Trichomonas vaginalis and Candida albicans. These sexually transmitted infections can also be transmitted from mother to child during pregnancy and childbirth by blood products, transplantation, graft

* Corresponding Author

Email:simplicekarou@hotmail.com and transfer or occasionally by other non-sexual ways (WHO 2007). Endogenous infections of the reproductive tract (RTI), including bacterial vaginosis and candidiasis, result from alterations in the balance of the normal protective bacterial flora of the female reproductive system. This flora consists mainly of Lactobacillus bacteria that produce hydrogen peroxide $\left(\mathrm{H}_{2} \mathrm{O}_{2}\right)$, an antiseptic that is associated with myeloperoxidase and hydrochloric acid mucus to form highly toxic to pathogens (Hainer et al.., 2001; Mitchell, 2004; Spencer et al.., 2007). In Burkina Faso, the combined efforts of government and its partners have achieved today a prevalence rate of $0.9 \%$ for HIV/AIDS (GARP Report 2014). The age range of 15-24 years is the most affected by this epidemic with a prevalence of $0.8 \%$ (GARP Report 2014). In adolescents, the health situation is influenced by early pregnancies, illegal abortions, early sex and unprotected, multi-partnership resulting in a high prevalence of HIV and STIs. The phenomenon is exacerbated by the low use of contraceptives and health services by young people. 
The lack of reproductive health service offering tailored to adolescents contributes greatly to the precarious situation of the 15-24 age health (National Health Development Plan 2010-2020). The reduction of the prevalence of sexually transmitted infections and reproductive tract infections in the young women could improve women's health and reduce the risk of acquiring HIV. Thus, the main objective of this study was to determine the prevalence of vaginal infections in women between 15 to 24 years in Ouagadougou, Burkina Faso.

\section{MATERIALS AND METHODS}

\section{Type and study site}

This is a descriptive and analytical study of the prevalence of vaginal infections conducted on young women of 15 to 24 years from April 2010 to February 2011 in Ouagadougou. The young women were recruited when visiting obstetrical service at the Medical Center Saint Camille of Ouagadougou and the national student assistance office for gynecological pains. Each patient sign a consent form to materialize her agreement to participate to the study. After the recruitment process, the nurse/midwife completed a baseline standardized questioner containing information about age, marital status, schooling, sexual activity and practices, first sex age, number of sexual partners, modern contraceptive use and HIV test screening. Information regarding the current vaginal problem and its history, a previous medical visit for the same problem was also collected on the questioner.

Then a physical and obstetrical examination is made by the nurse/midwife or the physician. After examination, the young woman is directed to the laboratory of the Medical Center Saint Camille of Ouagadougou for vaginal sample collection..

\section{Microbial isolation and identification}

All the participants were subjected to vaginal swabs in the laboratory of Saint Camille Medical Center in Ouagadougou. The microbial isolation and identification were performed on the collected samples at the Saint Camille Medical Centre using the conventional methods in vigor in the Centre. In brief the process included microscopic examination and the growth on selective culture media. Indeed, Gardnerella vaginalis was identified on the basis of the Amsel criteria including, acid $\mathrm{pH}>4.5$ of the vaginal discharge, the fishy odor of rotten clearance by the sniff test and the microscopic observation of "Clue cells". The other pathogenic bacteria were grown on chocolate agar+Polivitex, the confirmation of the identities was made with the Biomerieux API systems. Fungal strains were grown Sabouraud+Chloramphenicol. Antimicrobial susceptibility tests were performed as recommended by the French Society for Microbiology.

\section{Ethical issue}

This study received the approval from the Ethics Committee of the Saint Camille Medical Center and all participants signed an informed consent form.

\section{RESULTS}

\section{Sociodemographic characteristics of young women}

A total of 118 young women aged 15-24 years, mean age $21.8 \pm 2.01$, living in Ouagadougou were included in the study. The socio demographic data gathered are displayed in table 1 . According to the data in the table, the majority of them $(58.47 \%)$ were single; however all of them were sexually active. The half had their fist sex between 17 and 19 years, while $32 \%$ had their first sex after 20 years, the rest $(11.02 \%)$ went to their first sex before 17 years. For the periodicity, $50.85 \%$ of the surveyed women regularly go to sexual intercourses, while this is occasional for $47.46 \%$ of them. The majority had a fix partner, thus less than $2 \%$ asserted to have sexual intercourses with multiple partners. The contraception was used by approximately $40 \%$ of the surveyed, mainly the condoms. All the surveyed encountered at least once a vaginal problem, however only $54.24 \%$ of them had a previous gynecological consultation. Considering the HIV, the majority $(63.56 \%)$ knew their HIV serostatus.

Table 1: Sociodemographic characteristic and information on the participant sexual activity.

\begin{tabular}{lll}
\hline & & $\mathbf{N}(\mathbf{\%})$ \\
\hline Age & $15-20$ years & $31(26.27)$ \\
& $21-24$ years & $87(73.73)$ \\
\hline Marital status & Single & $69(58.47)$ \\
& Married & $49(41.53)$ \\
\hline Sexual activity & Yes & $118(100.00)$ \\
First sex age & $12-16$ years & $13(11.02)$ \\
& $17-19$ years & $59(50.00)$ \\
& 20 years and above & $38(32.20)$ \\
& Not informed & $8(6.78)$ \\
\hline Périodicity of sexual intercourse & Occasional & $56(47.46)$ \\
& Regular & $60(50.85)$ \\
& Not informed & $2(1.69)$ \\
\hline Number of sexual partner & One fixe Partner & $96(81.36)$ \\
& Multiple Partner & $2(1.69)$ \\
& Not informed & $20(16.95)$ \\
\hline Modern contraception & None & $38(32.20)$ \\
& Pills & $6(5.08)$ \\
& Condom & $41(34.75)$ \\
& Other methods & $9(7.63)$ \\
& Not informed & $24(20.34)$ \\
\hline Vaginal problem lasting & One week & $31(26.27)$ \\
& One month & $17(14.41)$ \\
& Two months & $70(59.32)$ \\
\hline Previous medical visit for the same & Yes & $64(54.24)$ \\
problem & No & $6(5.08)$ \\
& Not informed & $48(40.68)$ \\
\hline & No & $6(5.08)$ \\
& Not informed & $48(40.68)$ \\
& Yes & $75(63.56)$ \\
& No & $43(36.44)$ \\
\hline
\end{tabular}

\section{Vaginal infection}

The gynecological examination revealed that $87.29 \%$ of the women had an abnormal flora with more or less leucorrhea and for $73.73 \%$ of them the leucorrhea exceeded one month. The main cause of the gynecologic problem was a vaginal infection in $73.56 \%$ cases. Thus the microorganisms growth and identification was attempted for $64 \%$ samples (Figure 1). No Trichomonas vaginalis was found on the smears. Samples culture revealed the 
presence of several microorganisms, the most frequently isolated being Candida albicans, Staphylococcus spp. and Enterobacteria. The microbial distribution is presented in figure 2 .

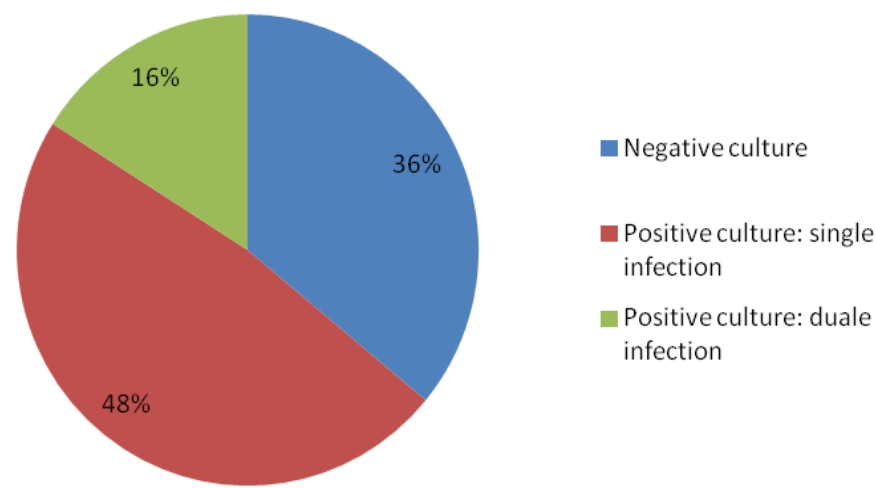

Fig. 1: Proportion of infected vaginal swabs.

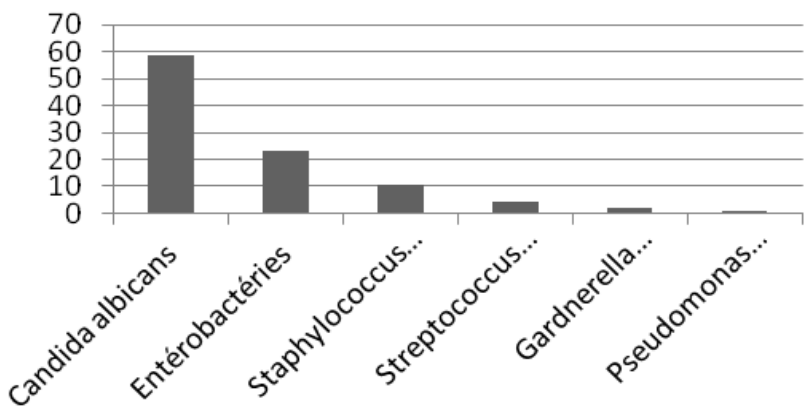

Fig. 2: Distribution of isolated pathogens from vaginal samples antifungal.

\section{Antimicrobial and antifungal susceptibility testing}

The susceptibility test revealed that all the isolated microorganisms resisted at least to one antibiotic or antifungal. Thus, the strains of Candida albicans were resistant to the following antifungals in the following rates miconazol $(18.18 \%)$, nystatin $(5.45 \%)$, econazol $(1.82 \%)$ and clotrimazol (1.82\%).

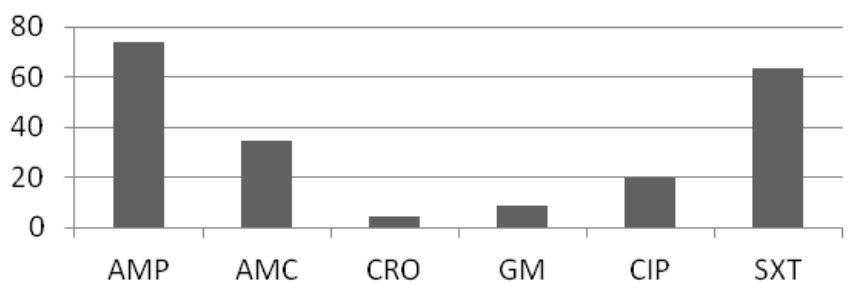

Fig. 3: Resistance to antibiotics AMP: ampicillin, AMC: amoxicillin + clavulanic acid, CRO: ceftriaxone, GM: gentamicin, CIP: ciprofloxacine, SXT: cotrimoxazole).

Figure 3 displays the antibiotic resistance pattern of the isolated bacterial strains. The tested antibiotics were beta-lactam antibiotics (ampicillin, amoxicillin + clavulanic acid, ceftriaxone), aminoglycosides (gentamicin), fluoroquinolones (ciprofloxacin) and cotrimoxazole. Ampicillin and cotrimoxazole were found to be less active with resistance rates of respectively $73.68 \%$ and $63.64 \%$; ceftriaxone remained the most efficient antibiotic with resistance rate of $4.35 \%$.

\section{DISCUSSION}

The present study aimed to investigate the main microorganisms implicated in vaginal infections in Ouagadougou. All the surveyed women were sexually active, and half of them had their first intercourses between 17 and 19 years. This reflects the reality of Burkina Faso because according the several surveys conducted in the country, the main age for the first sexual intercourses for girls is around 17 years (EDSBF-MICS IV, 2010). This trend is similar to the report of Stephenson et al. (2014) on the first sexual intercourse in African countries namely Burkina Faso, Ghana, Malawi and Uganda. The early sexual activity could be explained by the non-parent communication with their children about reproductive health in general (Somé et al., 2012) and also the influence of media, precarious family life conditions, strong presence of the opposite sex friends, proximity adolescents married or cohabiting (Stephenson et al., 2014). Among young women in this study, $32.2 \%$ did not use any means of protection during sex. The male condom is the main contraceptive method used, while the hormonal contraception is not widely used in this age group. These results are comparable to those of Bankole et al., (2014) who found that $32 \%$ of adolescents have unprotected sex. Failure in protection during sex remains a reality for these girls resulting in increasing the risk of sexually transmitted infections and unwanted pregnancy. Interestingly, the majority of the included subjects had HIV screening test, confirming knowledge of this infection. Among the women 15 to 49 years in Burkina Faso, the rate of use of modern contraception has remained stable from 2003 to 2010 (Hounton et al., 2015). The early sexual activity coupled with non-use of protective means during the sex makes girls more vulnerable to STIs and HIV/AIDS. Although HIV prevalence in this age group has declined over the years; it would be wise to continue prevention to avoid the risk of resurgence. The vaginal discharge is a common phenomenon among women in sexual activity and more often the result of an imbalance of vaginal flora by progressive disappearance of Lactobacillus. This imbalance can be due to infections, hormonal disturbances or other factors. All young women included in the study had a gynecological problem that required medical examination. About $87 \%$ of them had an abnormal flora with more or less abundant presence of vaginal discharge and for almost $75 \%$ of them, the duration of vaginal exceed one month. Theses findings are in accordance with previous studies conducted in Ouagadougou showing high prevalence of vaginal infections and low prevalence of co-infections in women with vaginal discharge (Karou et al., 2012; Sanou et al., 2014). As these previous reports, no Trichomonas vaginalis infection was detected in this study, although in South Africa, the prevalence of Trichomonas vaginalis infection was $6 \%$ in girls of 17-21 years, (Puran et al., 2014). The infection with Trichomonas vaginalis is a risk factor for acquiring HIV/AIDS (Moodley et al., 2002), thus the low proportion encountered in the present study is an encouraging result in the fight against HIV/AIDS in Burkina Faso. Candida albicans was the main pathogen causing gynecological problems in this study 
corroborating the results of Karou et al. (2012). By cons, the found prevalence seemed to be higher than that of Sanou et al. (2014). Other African countries also showed a low prevalence of vaginal Candida albicans infection, particularly in South Africa with a prevalence of 10\% among 17-21 years (Puran et al., 2014) and Ethiopia with $3.2 \%$ in women under age 20 and $7.3 \%$ among women 20 to 29 years (Mulu et al., 2015). The prevalence of bacterial vaginosis with Gardnerella vaginalis was very low, as in the report of Karou et al. (2012). These trends are comparable to those of Mulu in Ethiopia who had found a prevalence of 3.2\% among women under age 20 and $2.3 \%$ for those with an age between 20 and 29 years. However in South Africa, the prevalence of bacterial vaginosis in women aged 17 to 21 was $50 \%$. The imbalance of the vaginal bacterial flora can also cause the development of commensal bacteria that are enterobacteria, mainly E. coli, staphylococci and Streptococcus agalacitae. These commensal bacteria are the main responsible for early neonatal infections when the newborn is infected while passing through the vaginal tract colonized by these bacteria (Camacho-Gonzalez et al.. 2013). Their control during pregnancy especially during the third trimester of pregnancy may contribute to the fight against early neonatal infections. The resistances to antibiotics and antifungals are a public health problem and a threat to the population and should be better monitored to better control strategy. In our study, 64 young women had suffered a medical consultation for vaginal and $78.13 \%$ of them received treatment through the empirical therapy using a simplified algorithm diagnosis and treatment of vaginal infections introduced by the health authorities of Burkina Faso in 1996. In addition, among these young women who previously consulted, $71.86 \%$ of them said that the treatment was ineffective. This inefficiency could be explained by the failure to eliminate the responsible pathogens. This causes the development of resistance phenomena to antibiotics and antifungals that may be encountered. In this study, clotrimazole and econazole have proven very effective against Candida albicans strains isolated, on the other hand, miconazole exhibits fair resistance. Our results corroborate those of Sanou et al. who found resistance prevalences of $23.1 \%$ for miconazole, nystatin $6 \%$ and $0 \%$ for fluconazole (Sanou et al. 2014). These results show a decrease in the effectiveness of miconazole for the treatment of vaginal candidiasis, therefore a surveillance should be enhanced to address the problem of antimicrobial resistance. Bacteria isolated were mostly resistant to ampicillin and cotrimoxazole. Resistance to penicillins and cotrimoxazole are very common as more and more isolated bacteria produce betalactames that inactivate beta-lactam antibiotics (Weiner et al.. 1999).

\section{CONCLUSION}

The imbalance in the vaginal flora by progressive disappearance of Lactobacillus due to sexually transmitted infections increases the vulnerability of women to HIV/AIDS infection. Candida albicans and other bacteria are the main cause of gynecological problems encountered in women aged 15 to 24 in Ouagadougou, manifesting most often by an imbalance of vaginal flora that are recurring. Antifungal agents commonly used are still very effective against Candida albicans except miconazole. The colonization of the vaginal tract by E. coli, Staphylococcus aureus and Streptococcus agalactiae should be better monitored during pregnancy to prevent early neonatal infection.

\section{AKNOWLEGEMENT}

We are thankful to all the departmental technical staff of the national student assistance office in Ouagadougou and Saint Camille Medical Center, Ouagadougou. We are grateful to all the participant women for their kind cooperation.

Financial support and sponsorship: The study was supported by the government of Burkina Faso through the project on multisectorial national plan of HIV/AIDS (PA-PNM) and the national student assistance office.

Conflict of Interests: There are no conflicts of interest.

\section{REFERENCES}

Bankole A, Ahmed FH, Neema S, Ouedraogo C and Konyani S. Knowledge of correct condom use and consistency of use among adolescents in four countries in Sub-Saharan Africa. Afr J Reprod Health, 2007; 11(3): 197-220.

Camacho-Gonzalez A, Spearman PW and Stoll BJ. Neonatal infectious diseases: evaluation of neonatal sepsis. Pediatr Clin North Am, 2013; 60(2): 367-389.

Elia D. La vaginose bactérienne. Genesis, 2004; 101: 21-25.

Hainer BL and Gibson MV. Vaginitis: diagnosis and treatment. American Family Physician, 2001; 83(7): 807-815.

Hounton S, Barros AJD, Amouzou A, Shiferaw S, Maiga A, Akinyemi A, Friedman $\mathrm{H}$ and Koroma D. Patterns and trends of contraceptive use among sexually active adolescents in Burkina Faso, Ethiopia, and Nigeria: evidence from cross-sectional studies. Glob Health Action, 2015; 8: 29737.

Institut National de la Statistique et de la Démographie (INSD), Ouagadougou, Burkina Faso, Enquête démographique et de santé et à indicateurs multiples, EDSBF-MICS IV. 2010. 40 pages.

Karou SD, Djigma F, Sagna E, Nadembèga C, Zéba M, Kabré A, Anani K, Ouermi D, Gnoula C, Pietra V, Pignatelli S and Simpore J, Antimicrobial resistance of abnormal vaginal discharges microorganisms in Ouagadougou, Burkina Faso. Asian Pac J Trop Biomed, 2012; 2(4): 294-297.

Keane F, Ison CA, Noble $\mathrm{H}$ and Estcourt C. Bacterial vaginosis. Sex Transm Inf, 2006; 82: 16-18.

Lawn SD. AIDS in Africa: the impact of coinfections on the pathogenesis of HIV-1 infection. J Infect, 2003; 48: 1-12.

Macsween KF and Ridgway GL. The laboratory investigation of vaginal discharge. J Clin Pathol, 1998; 51: 564-567.

McClelland RS, Richardson BA, Graham SM, Masese LN, Gitau R, Lavreys L, Mandaliya K, Jaoko W, Baeten JM and NdinyaAchoa JO. A prospective study of risk factors for bacterial vaginosis in HIV-1 seronegative Africain women. Sex Transm Dis, 2008; 35(6): 617623.

Ministère de la Santé Burkina Faso. Plan national de développement sanitaire 2011-2020.

Mitchel H. ABC of sexually transmitted infection. Vaginal discharge, causes, diagnosis and treatment. BMJ, 2004; 328: 1306-1308.

Moodley P, Connolly C and Sturm AW. Interrelationships among Human Immunodeficiency Virus type 1 infection, bacterial 
vaginosis, trichomoniasis, and the presence of yeasts. JID, 2002; 185: 6973.

Mulu W, Yimer M, Zenebe Y and Abera B. Common causes of vaginal infections and antibiotic susceptibility of aerobic bacterial isolates in women of reproductive age attending at Felegehiwot referral Hospital, Ethiopia: a cross sectional study. BMC Women's Health, 2015; 15:42.

OMS 2007. Stratégie mondiale contre les infections sexuellement transmissibles 2006-2015.

ONUSIDA 2014. Fiche d'information statistiques mondiales

2014.

ONUSIDA, Rapport d'activité sur la riposte au SIDA au Burkina Faso GARP 2014.

Puran AC, Adler D, Wallace M, Bennie T, Phuti A, Abar B and Bekker LG. Incidental Findings of Bacterial Vaginosis and Other Infections in Papanicolaou Smears of HIV-infected and HIV-uninfected Adolescent Females in South Africa. J AIDS HIV Res, 2014; 6(9): 172 176

Sanou I, Millogo-Traore' F, Bicaba I,Toure' B, Soudre' F Etiologie des infections vaginales à Ouagadougou, Burkina Faso. Med Santé Trop, 2014.; 24: 430-431.

Somé DT, Somé DA, Hien H, Diallo R, Zinguei D, Diallo I Diaggouda $S$ and Dao B. Santé sexuelle et reproductive des adolescentes de Bobo Dioulasso, Burkina Faso: place de la communication parentsadolescentes pour la réduction des risques. Pan Afr Med J, 2012; 11:65. 1147-1151

Spence D and Melville C. Vaginal discharge. BMJ, 2007; 335:

Stephenson R, Simon C and Finneran C. Community factors shaping early age at first sex among adolescents in Burkina Faso, Ghana, Malawi and Uganda. J Health Popul Nutr, 2014; 32 (2): 161-175.
Van de Wijgert JH, Morrison CS, Cornelisse PG, Munjoma M, Moncada J, Awio P, Wang J, Var der Pol B, Chapito T, Salata RA and Padian NS. Bacterial vaginosis and vaginal yeast, but not vaginal cleansing, increase HIV-1 acquisition in African women. J Acquir Immune Defic Syndr, 2008; 48(2): 203-10.

Warren D, Klein RS, Sobel J, Kiele B, Brown W, Schuman P, Jean Anderson, Cu-Uvin S, Mayer K, Jamieson DJ, Holmberg S and Duerr A for the HIV Epidemiology Research Study Group. A multicenter study of bacterial vaginosis in women with or at risk for human immunodeficiency virus infection. Infec Dis Obst Gynecol, 2001; 9: 133 141.

Weiner J, Quinn JP, Bradford PA, Goering RV, Nathan C, Bush $\mathrm{K}$ and Weinstein RA. Multiple antibiotic-resistant Klebsiella and Escherichia coli in nursing homes JAMA, 1999; 281 (6): 517-523.

White DJ and Vanthuyne A. Vulvovaginal candidiasis. Sex Transm Inf, 2006; 82: 28-30.

\section{How to cite this article:}

Nadembega CW, Djigma F, Ouermi D, Karou SD, Simpore J. Prevalence of vaginal infection in 15 to 24 years women in Ouagadougou, Burkina Faso. J App Pharm Sci, 2017; 7 (01): 209213. 